Article

\title{
A Comparison of the Mineral Dust Absorptive Properties between Two Asian Dust Events
}

\author{
Timothy Logan ${ }^{1}$, Baike $\mathrm{Xi}^{1}$ and Xiquan Dong ${ }^{1,2, *}$
}

1 Department of Atmospheric Sciences, University of North Dakota, 4149 University Avenue, Stop 9006, Grand Forks, ND 58202, USA; E-Mails: timothy.logan@my.und.edu (T.L.); baike@aero.und.edu (B.X.)

2 GCESS, Beijing Normal University, Beijing 100875, China

* Author to whom correspondence should be addressed; E-Mail:dong@aero.und.edu; Tel: +1-701-777-6991; Fax: +1-701-777-5032.

Received: 14 November 2012; in revised form: 21 January 2013 / Accepted: 21 January 2013 / Published: 28 January 2013

\begin{abstract}
Asian dust events are generated by deep convection from strong low pressure systems that form over mineral dust source regions. This study compares the mineral dust optical properties of two strong Asian dust events from the winter (December 2007) and spring (March 2010) seasons using AERONET retrieved parameters from three sites along the dust event path: SACOL (dust source region), Xianghe (downwind mixed aerosol region), and Taihu (downwind pollution region). The parameters include: aerosol effective radius, optical depth $(\tau)$, absorptive optical depth $\left(\tau_{a b s}\right)$, their respective wavelength dependences or Angstrom exponents ( $\alpha$ and $\alpha_{a b s}$ ), and the spectral single scattering albedo $\left(\omega_{o}(\lambda)\right)$. The $\alpha_{440-870}$ values in both cases do not exceed 0.62 indicating coarse mode particle dominance at all three sites. The winter case is shown to have carbonaceous influences at all three sites as given by $\alpha_{a b s 440-870}$ between 1.3 and 1.8 with strong spectral $\tau_{a b s}$ absorption. The spring case is more dust dominant with $\alpha_{a b s 440-870}$ of 1.7-2.5 (noting that the largest value occurred at Taihu) with strong $\tau_{a b s}$ absorption primarily in the visible wavelengths. Comparison studies between the observed and theoretically calculated $\omega_{o}(\lambda)$ for the winter and spring cases have shown an excellent agreement except for the winter case at Taihu due to pollution influences. The comparison studies also suggest that $\omega_{0}(\lambda)$ is more sensitive to particle absorptive properties rather than particle size. The sharp increase in the aerosol radiative effect (ARE) during the dust events with $\mathrm{ARE}_{\mathrm{BOA}}>\mathrm{ARE}_{\mathrm{TOA}}$ suggests a stronger aerosol cooling effect at the surface than at the TOA.
\end{abstract}


Keywords: mineral dust; Asian dust events; aerosol absorptive properties

\section{Introduction}

Asian dust events are typically spring season events but have been known to occur at any time of the year [1-4]. Strong low pressure systems that create dry convection facilitate favorable conditions for surface winds to loft loose desert sand and soil into the mid-troposphere ( $\sim 5 \mathrm{~km}$ or $500 \mathrm{hPa}$ level) where it can be transported for thousands of kilometers [2,4-7]. Continuing urbanization and industrialization in Asia causes concern since anthropogenic carbonaceous particles such as black carbon (BC), organic carbon (OC), and biomass burning aerosols along with sulfates and nitrates have been known to mix and condense onto mineral dust, thus altering the optical properties of the particles $[6,8-10]$. Due to the variety of scattering and absorbing aerosols generated as a result of these secondary reactions, the radiative balance of the atmosphere is altered by the aforementioned first aerosol effect while the second aerosol effect deals with influences on cloud physical properties (e.g., lifetime, brightness, droplet size distribution and precipitation) [1,4,11-15]. Aerosol effects can also be locally detrimental as they create increased health risks especially for susceptible populations [16].

Two Asian dust events during the winter (24-31 December 2007) and spring (15-21 March 2010) seasons provide a unique opportunity to compare the seasonal and regional dependences of mineral dust absorptive properties. Both dust events passed over the same regions in northern, west-central, and eastern China before they exited the mainland, subsequently affecting the remote Pacific Ocean before dissipating (MODIS visible images not shown). However, the aerosol types in these regions have shown a diverse seasonal dependence [8,10,17]. For example, northern China usually has strongly absorbing aerosols in the winter due to $\mathrm{BC}$ and $\mathrm{OC}$ particle emissions from industrial and urban emissions (e.g., residential heating) while the spring season is dominated by emissions from the Gobi desert upwind of the area [18,19]. West-central China is not only plagued by episodic dust events (more common in the spring) but can also have pollution influences from the few mega-cities in that region [7,18,20]. Eastern China is dominated by large urban centers that generate pollution throughout the year and can also be affected by dust events from both the Gobi and Taklamakan deserts (though not as strongly as west-central China) $[18,21]$.

This study uses the parameters of aerosol optical depth $(\tau)$, absorption aerosol optical depth $\left(\tau_{a b s}\right)$, their respective spectral wavelength dependences: Angstrom exponent $(\alpha)$ and absorption Angstrom exponent $\left(\alpha_{a b s}\right)$, and the spectral single scattering albedo, $\left(\omega_{o}(\lambda)\right.$ ), (ratio of the scattering and extinctive aerosol properties) in order to (1) illustrate the seasonal differences of the absorptive properties of the mineral dust, (2) use the spectral wavelength dependences to report the influences of anthropogenic carbonaceous particles on naturally occurring mineral dust, and (3) compare the single scattering properties from three selected ground-based AERONET (Aerosol Robotic Network) remote sensing platforms (SACOL, Xianghe, and Taihu) to theoretically calculated ones from a mineral dust model [22]. 


\section{Data and Methodology}

\subsection{AERONET}

The AErosol RObotic NETwork is a worldwide framework of CIMEL sun/sky photometers that retrieve aerosol optical data at discrete wavelengths ranging from 340 to $1,020 \mathrm{~nm}[19,23]$. This study employs Level 2.0 data to ensure cloud screened, quality controlled retrievals of $\tau, \tau_{a b s}, \alpha, \alpha_{a b s}$, and $\omega_{o}$ in the wavelength range between 440 and $1,020 \mathrm{~nm}$ [24]. The retrievals are derived from inverted almucantar observations developed by [25] and [26]. We use the daily averaged data collected from three AERONET sites representing west-central, northern, and eastern China: 28 December 2007 and 20 March 2010 (SACOL) and 29 December 2007 and 21 March 2010 (Xianghe and Taihu). We use retrievals where $\tau_{440}>0.4$ to ensure the least amount of uncertainty [19].

From Figure 1, SACOL $\left(35.95^{\circ} \mathrm{N}, 104.14^{\circ} \mathrm{E}\right)$, the Semi-Arid Climate and Environment Observatory of Lanzhou University, is within a mineral dust source region in the Gansu province downwind from the Taklamakan and Gobi Deserts as well as within the confines of the Loess Plateau [7,17]. It is also nearby to Lanzhou City which has a population of over 3 million inhabitants along with strong urban and industrial influences [18]. Xianghe $\left(39.75^{\circ} \mathrm{N}, 116.96^{\circ} \mathrm{E}\right)$ is in an aerosol mixture region affected by mineral dust, biomass aerosols, and pollution from nearby Beijing and other urban areas in northeast China $[4,18]$. Taihu $\left(31.4^{\circ} \mathrm{N}, 120.21^{\circ} \mathrm{E}\right)$ lies within a heavily polluted region upwind of Shanghai but is itself surrounded by numerous industrial influences $[9,18]$.

Figure 1. Locations of three selected AERONET sites and the desert source regions. Note that SACOL is directly downwind of three mineral dust sources while Xianghe is primarily influenced by the eastern Gobi Desert.

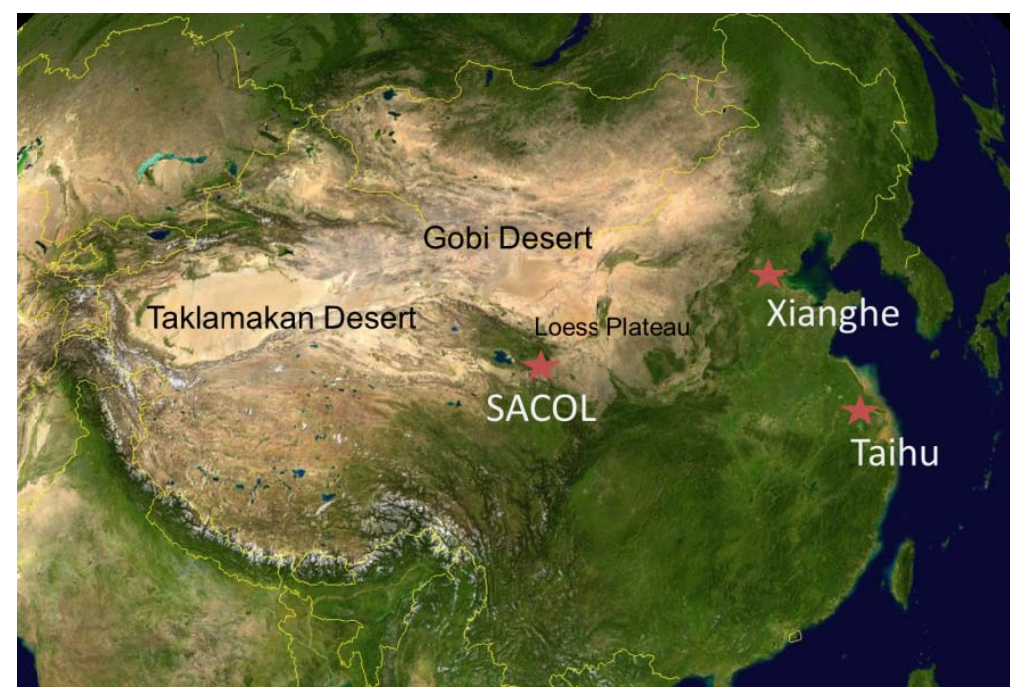

\subsection{Theoretical Mineral Dust Model}

This study investigates the optical properties of mineral dust particles which are typically non-spherical in nature. In fact, the optical properties require special consideration since AERONET retrievals are primarily based on assumptions that atmospheric aerosols are homogeneous spherical particles [22,25,27]. As pointed out by [28], though there are shortcomings to using these assumptions 
in AERONET retrievals, it is still possible to gain useful information from the almucantar readings $[25,28]$. This study employs the use of a mineral dust model that is comprised of a spectral database calculated from mathematical and geometric theory [20,22]. The model contains theoretical calculations of the single scattering parameters of mineral dust aerosols by assuming a tri-axial ellipsoidal geometric shape which offers many advantages over calculations based on spherical (Mie Theory) and spheroidal assumptions which illustrates the most representative shape of mineral dust particles to date $[20,22]$.

The [22] model uses a combination of Lorenz-Mie theory, the T-matrix method, discrete dipole approximation (DDA), and an improved geometric optics method (IGOM) to illustrate the optical properties of mineral dust-like aerosols. The results are compiled into a database that requires the knowledge of the particle aspect ratio (ratio of the semi-major to semi-minor axis assuming ellipsoidal geometry), size parameter (based on retrieved effective radius), and complex index of refraction. A more detailed discussion of the database as well as the methodology can be found in [22]. Though the database contains information about the phase matrix, extinction efficiency, extinction, scattering and absorption coefficients, and single scattering albedo, this study uses the latter to compare with AERONET retrievals.

We will consider the AERONET retrievals as truth and compare these retrievals with the theoretical calculations from the mineral dust model because the model will have inherent shortcomings when dealing with aerosol mixtures (e.g., external/internal mixtures and pollution coating). Since AERONET retrievals are based on spheroidal assumptions (rather than ellipsoidal) it would be informative to note the agreement between the two retrieval mechanisms in order to gain more insight on their limitations. This will be done by performing a comparison study using the AERONET retrieved effective radius and complex index of refraction $\left(m_{r}+m_{i}\right)$ as inputs of the mineral dust model.

\subsubsection{Comparison Study of $\omega_{o}(\lambda)$ Involving the Aerosol Effective Radius and Complex Index of Refraction}

The theoretical database is arranged in a manner that accounts for five dimensions regarding: two aspect ratios, one size parameter, and the complex index of refraction (real and imaginary parts) [22]. The complex index of refraction is obtained directly from the AERONET retrievals with an uncertainty of up to $30 \%$ when $\tau_{440}>0.5$ [26]. The size parameter $(x)$ at each wavelength $(\lambda)$ is calculated from the AERONET retrieved effective radius $\left(r_{e f f}\right)$ and is given by,

$$
x=\frac{2 \pi r_{e f f}}{\lambda}
$$

where $\lambda$ is in discreet wavelengths of $440,675,870$, and $1,020 \mathrm{~nm}$. In this way, a single value of $\omega_{o}$ at each wavelength is obtained from the database to yield a theoretical spectral wavelength dependence to go along with the AERONET retrieved spectral dependence. The aspect ratios are assumed values based on the best fit between the theoretical and observational $\omega_{o}$ spectral dependence curve to within one standard deviation. We will vary the effective radius and complex index of refraction while keeping one of these parameters constant in order to perform the comparison study and discuss the results in Section 3.3. 


\section{Results and Discussions}

\subsection{Synoptic Pattern of the Two Dust Events}

Figure 2(a,b) shows the $850 \mathrm{hPa}$ geopotential heights for the 24-31 December 2007 (winter case) and 15-21 March 2010 (spring case) time spans. The mean synoptic patterns of both cases have similar trough (darker purple) locations over Northeastern China/Southern Russia. However, the ridge (red and orange) locations differ by ten degrees of latitude with the winter case ridge position $\left(43^{\circ} \mathrm{N}\right)$ being at a higher latitude than the spring case $\left(33^{\circ} \mathrm{N}\right)$. The position of the ridge in relation to the trough is also different between the two cases suggesting different wind flow patterns $[8,29]$. For example, there is more of a northwesterly flow over Xianghe than at Taihu and SACOL in the winter case but a west-northwesterly flow pattern is evident in the spring case at all three sites. From backward trajectory analysis (not shown) both storms had origins in the Loess Plateau (Western Gobi Desert) region but the wind patterns suggest dust from the eastern Gobi Desert may have impacted Xianghe more than SACOL and Taihu for the winter case. In contrast, the spring case wind pattern and subsequent track of the low pressure system advected dust from the Loess Plateau to all sites. The synoptic patterns for both cases illustrate how the absorptive properties of the mineral dust aerosols can change depending on the season which is discussed in the following section $[7,8,29]$.

Figure 2. (a) $850 \mathrm{hPa}$ geopotential heights showing the low pressure (purple) and high pressure systems (orange) and the inferred wind patterns as a result of their positions for the winter and (b) spring cases. Image provided by [30,31].

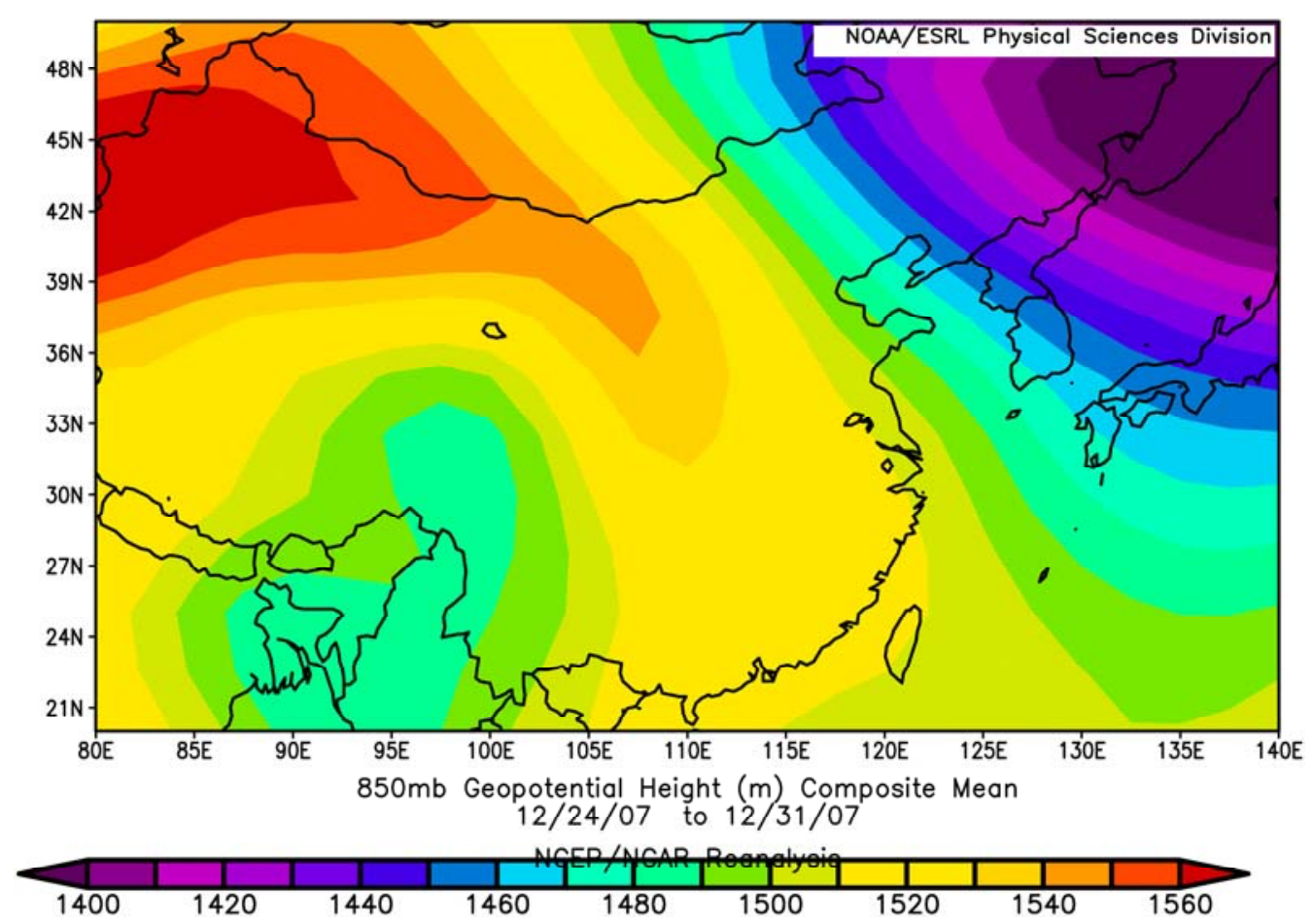

(a) 
Figure 2. Cont.

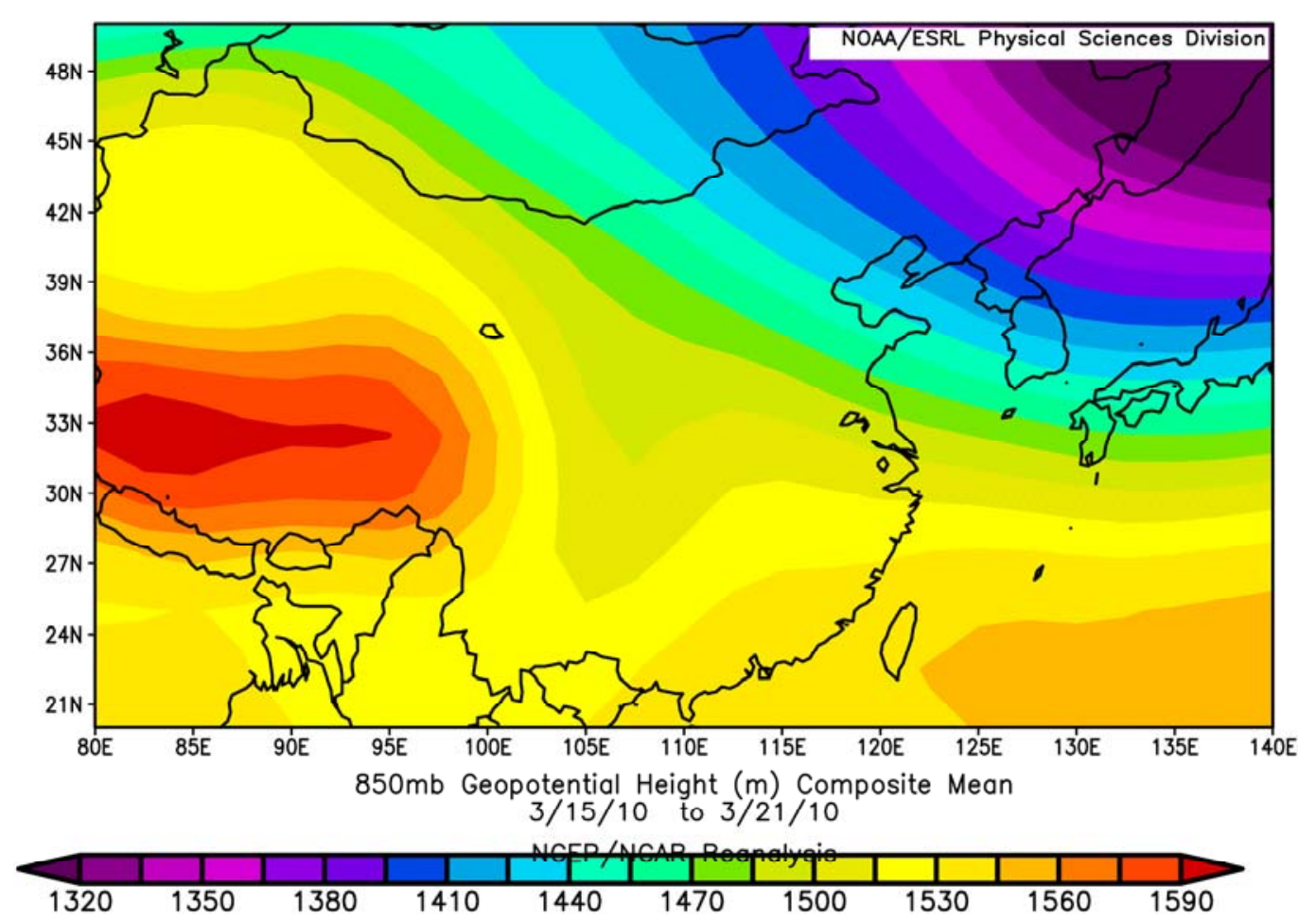

(b)

\subsection{Mineral Dust Properties Inferred from the Particle Volume Size Distribution, $\tau, \tau_{a b s}, \alpha_{440-870,}$ and} $\alpha_{a b s 440-870}$ Parameters

Figure 3(a,b) shows the size distributions of the winter and spring cases, respectively. For the winter case, SACOL and Xianghe have similar volume coarse mode magnitudes and primarily have unimodal distributions. There is a small fine mode contribution $\left(r_{\text {eff-fine }} \sim 0.085 \mu \mathrm{m}\right)$ at SACOL indicating pollution from the nearby city of Lanzhou [18]. There is a smaller, yet discernible fine mode contribution at Xianghe $\left(r_{\text {eff-fine }} \sim 0.15\right)$ which indicates anthropogenic influences from Beijing and surrounding areas [19]. The coarse mode magnitude at Taihu is nearly half compared to the other sites but the fine mode contribution $\left(r_{\text {eff-fine }} \sim 0.45\right)$ is likely due to industrial influences in the vicinity as well as urban influences from Shanghai [9]. The spring case exhibits a strong mineral dust signature at all three sites as there is a more pronounced unimodal coarse mode contribution. The lack of a discernible fine mode peak suggests that mineral dust dominates the size distribution in this case though pollution particles may still be present in the atmosphere.

The wavelength dependences of $\tau$ for the winter and spring cases are shown in Figure 4. SACOL has the weakest wavelength dependence of all three sites for both the winter and spring cases indicating coarse mode particles ( $\alpha_{440-870}$ of 0.29 and 0.11 , respectively). This is due to a close proximity to various mineral dust source regions (Taklamakan and Gobi Desert and the Loess Plateau) [7,17]. However, the wavelength dependence for the winter case is stronger suggesting a noticeable more of a fine mode influence than in the spring case. At Xianghe, the stronger wavelength dependence and higher $\alpha_{440-870}$ values $(0.42-0.48)$ suggest more of a fine mode influence for both cases than at SACOL. Taihu has the strongest wavelength dependence in the winter case with $\alpha_{440-870}$ of 0.62 indicating a mixture of coarse and fine modes due to an abundance of pollution particles resulting from 
stagnant winter season air patterns that allow for increased aerosol loading $\left(\tau_{440} \sim 1.3\right)$ [32]. In the spring, there is much less wavelength dependence at Taihu suggesting coarse mode particles dominate the aerosol extinctive properties similar to the SACOL case. It is interesting to note that the $\alpha_{440-870}$ value of 0.15 at Taihu illustrates the overwhelmingly large magnitude of dust particles in the spring as compared with the winter case. Since all sites have $\alpha_{440-870}$ values less than 0.62 , it can be concluded that coarse mode particles dominated the aerosol size properties along with some influences from the fine mode (e.g., pollution).

Figure 3. (a) Particle volume size distributions of the winter and (b) spring cases.

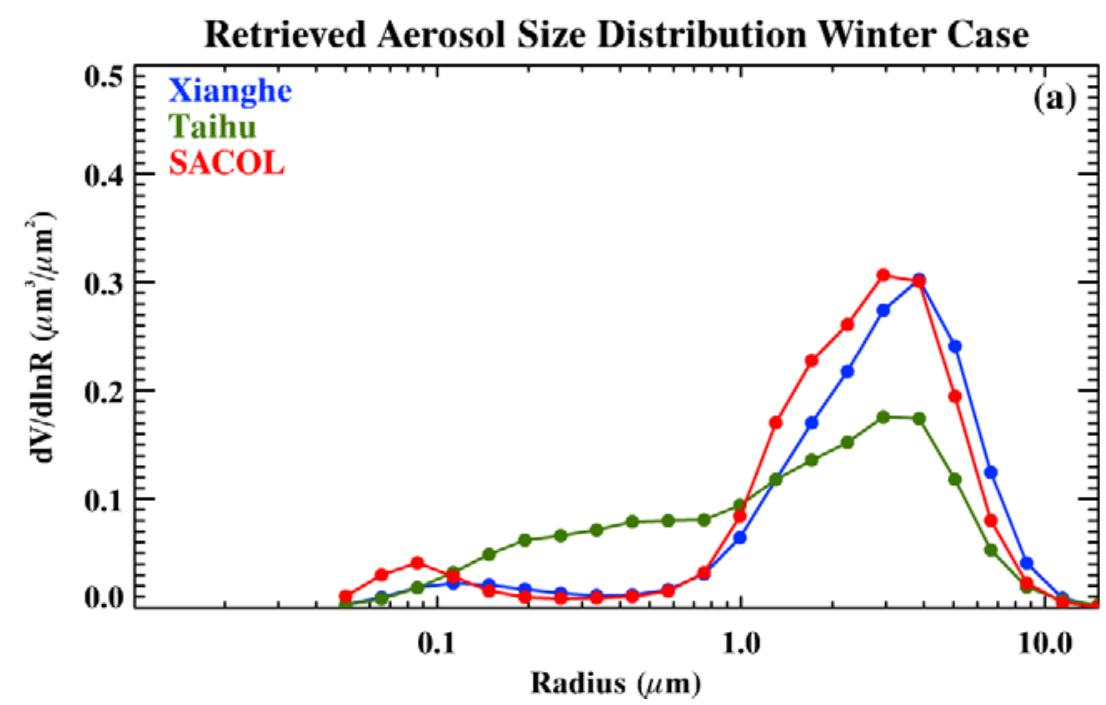

(a)

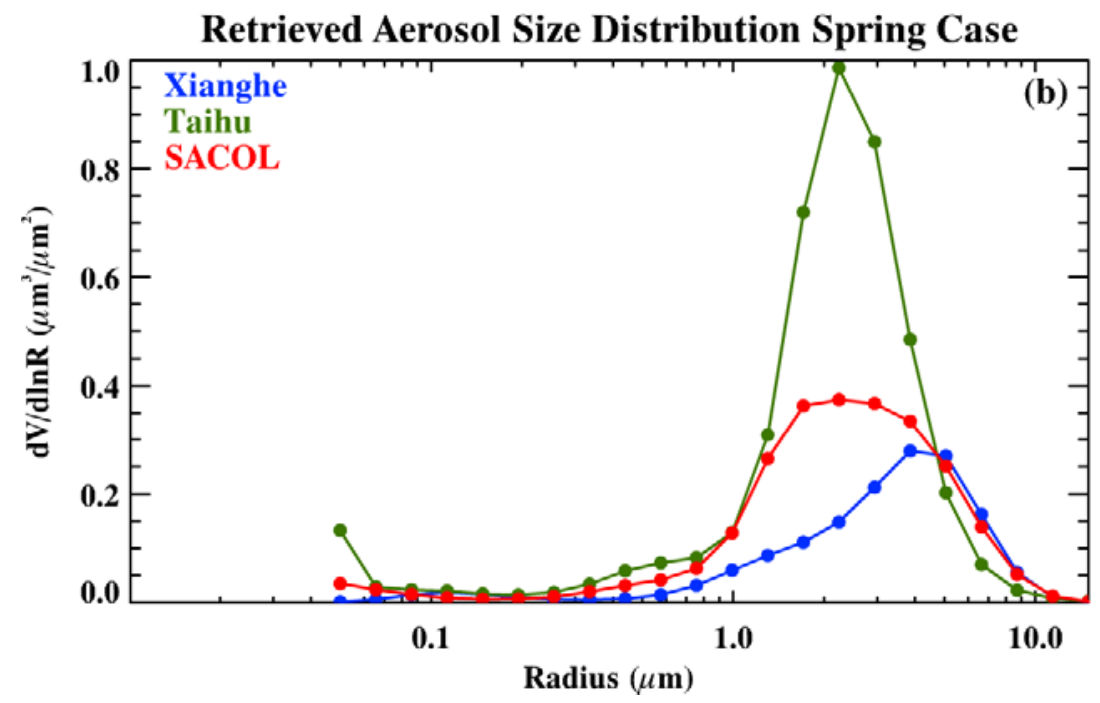

(b) 
Figure 4. (a) Wavelength dependence of $\tau$ for the winter and (b) spring cases. The normalized $\tau$ values at each wavelength are ratios to the $\tau_{440}$ value in order to compare the wavelength dependences across the three sites.
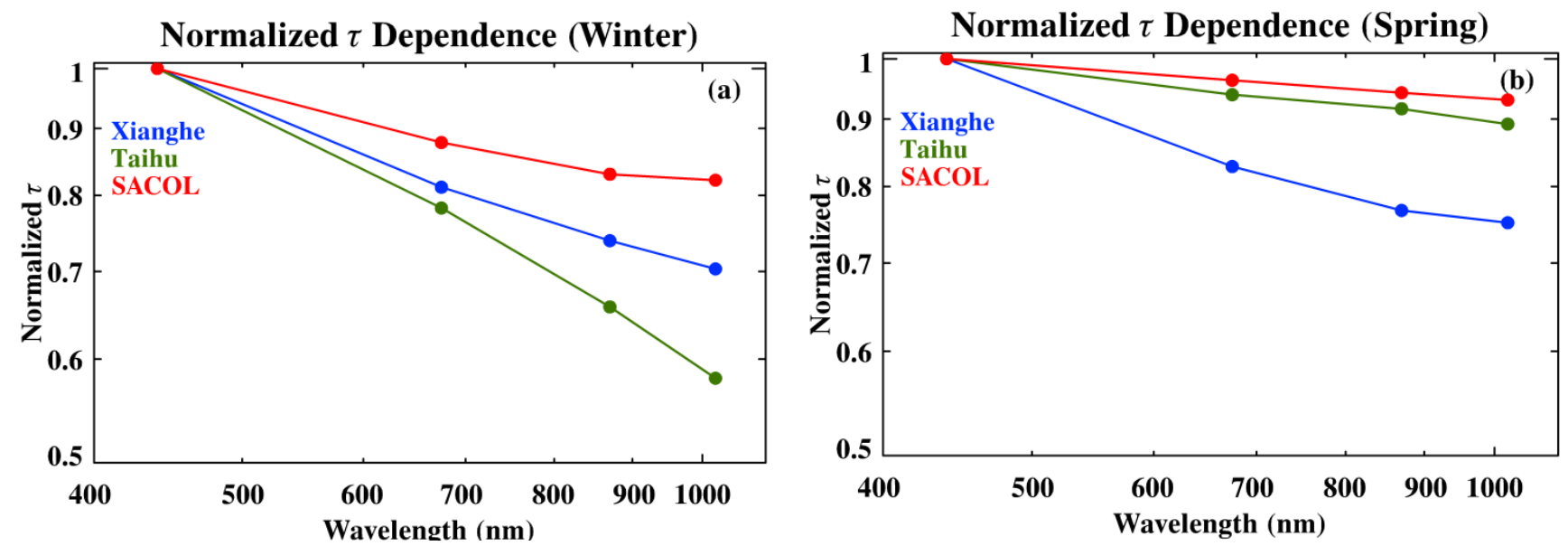

Figure 5 shows the wavelength dependence of $\tau_{a b s}$. The wavelength dependence is slightly stronger for the winter case than for the spring case. The winter $\alpha_{a b s 440-870}$ value of 1.8 represents a typical value for dust due to the strong absorption in the visible and weak absorption in the near IR [32-34], while the spring $\alpha_{a b s 440-870}$ value of 1.6 indicates a mineral dust influence with possible carbonaceous influences [18,32,34]. Taihu has a weaker wavelength dependence than Xianghe and nearly identical to SACOL in the winter case. The lower $\alpha_{a b s 440-870}$ of 1.3 indicates a strong BC influence given by a weaker wavelength dependence across the visible and near IR [32]. It should be noted that OC tends to strengthen the absorption in the visible leading to an even higher $\alpha_{a b s 440-870}$ value [33]. For the spring case, Taihu has the strongest wavelength dependence in both the visible and near IR indicating a robust mineral dust influence $\left(\alpha_{a b s 440-870} \sim 2.5\right)$ [32-34]. The spring case at SACOL is more indicative of mineral dust influences with $\alpha_{a b s 44-870}$ of 1.7. Table 1 summarizes the AERONET retrieved parameters used in this study. The following section will discuss how well the theoretically calculated $\omega_{o}(\lambda)$ at different wavelengths agree with AERONET retrievals at the three sites for the selected two cases.

Figure 5. (a) Wavelength dependence of $\tau_{a b s}$ for the winter and (b) spring cases. The normalized $\tau_{a b s}$ values at each wavelength are ratios to the $\tau_{a b s 400}$ value in order to compare the wavelength dependences across the three sites.
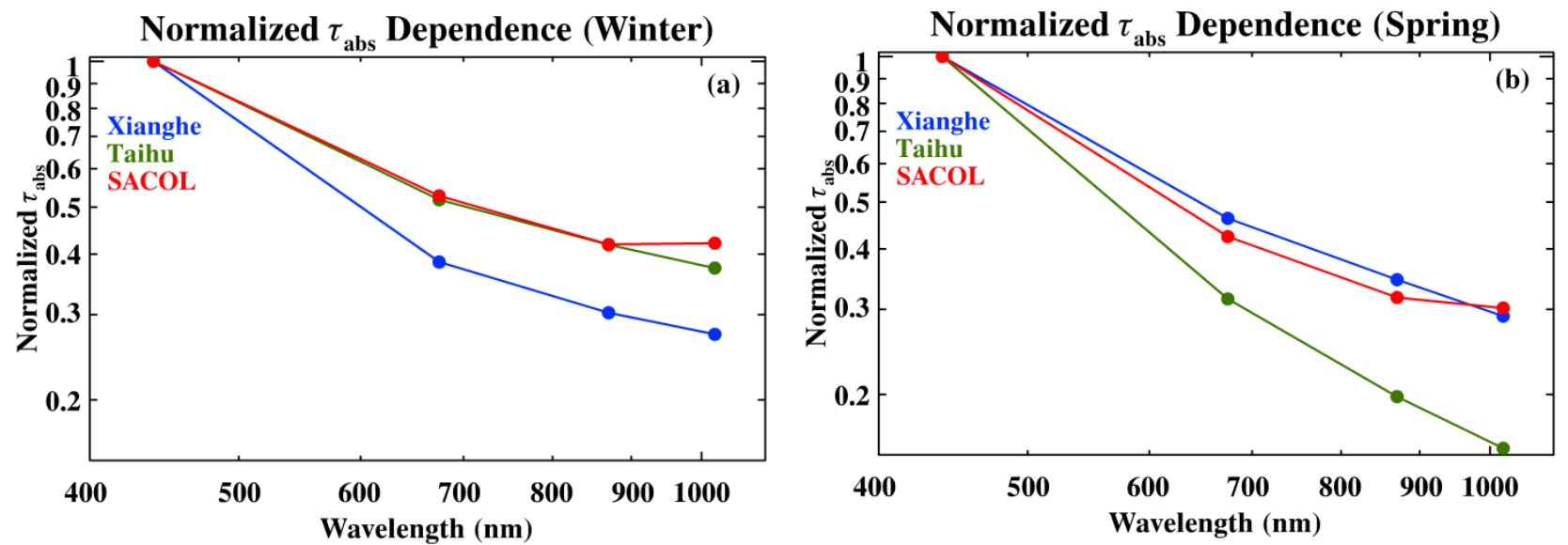
Table 1. Summary of the AERONET retrieved aerosol optical properties for the winter and spring cases.

\begin{tabular}{ccccccc}
\hline AERONET Site & $\boldsymbol{\tau}_{440}$ & $\boldsymbol{\alpha}_{\mathbf{4 4 0 - 8 7 0}}$ & $\boldsymbol{\alpha}_{a b s 40-870}$ & $\boldsymbol{m}_{\boldsymbol{r}}$ & $\boldsymbol{m}_{\boldsymbol{i}}$ & $\boldsymbol{r}_{\text {eff }}$ \\
\hline SACOL (winter) & 0.6 & 0.29 & 1.3 & 1.46 & 0.003 & 0.77 \\
SACOL (spring) & 0.8 & 0.11 & 1.7 & 1.57 & 0.004 & 0.97 \\
Xianghe (winter) & 0.6 & 0.48 & 1.8 & 1.60 & 0.005 & 1.07 \\
Xianghe (spring) & 0.5 & 0.42 & 1.6 & 1.60 & 0.004 & 1.25 \\
Taihu (winter) & 1.3 & 0.62 & 1.3 & 1.53 & 0.022 & 0.59 \\
Taihu (spring) & 1.4 & 0.15 & 2.5 & 1.53 & 0.004 & 0.80 \\
\hline
\end{tabular}

\subsection{Comparisons of $\omega_{o}(\lambda)$ between Theoretical Calculations and AERONET Retrievals}

Figures 6 and 7 present the comparisons of $\omega_{0}(\lambda)$ values at wavelengths of $440-1,020 \mathrm{~nm}$ retrieved from three AERONET sites to those calculated by a mineral dust model for the winter and spring cases. In order to demonstrate the wavelength dependences of $\omega_{o}$ to the index of refraction and aerosol particle size, the index of refraction is held constant while the effective radius varies in Figure 6 and vice versa in Figure 7. Although the model results are summarized in Table 2, we focus on the following key discussion points at the SACOL, Xianghe and Taihu sites.

Figure 6. (a) Comparison between the observed (solid) and theoretically calculated (dashed) $\omega_{o}$ for the winter (red circle) and spring (blue box) cases at SACOL, (b) Xianghe, and (c) Taihu. The measured complex index of refraction and the effective radii were used as inputs of the model calculation where the complex index of refraction is held constant while the effective radius varies.
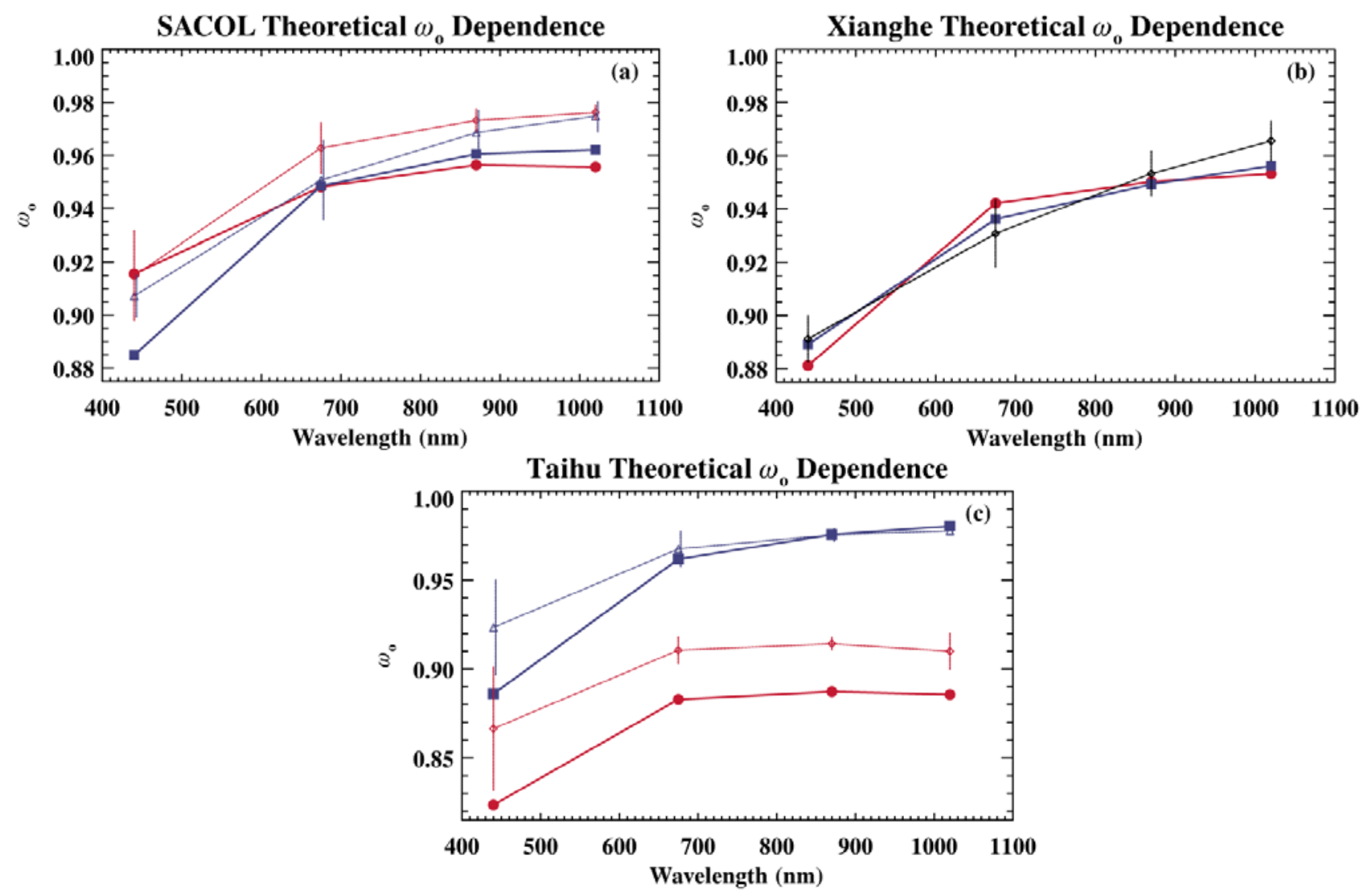
Figure 7. (a) Comparison between the observed (solid) and theoretically calculated (dashed) $\omega_{o}$ for the winter (red circle) and spring (blue box) cases at SACOL, (b) Xianghe, and (c) Taihu. The measured complex index of refraction and the effective radii were used as inputs of the model calculation where the effective radius is held constant while the index of refraction varies.
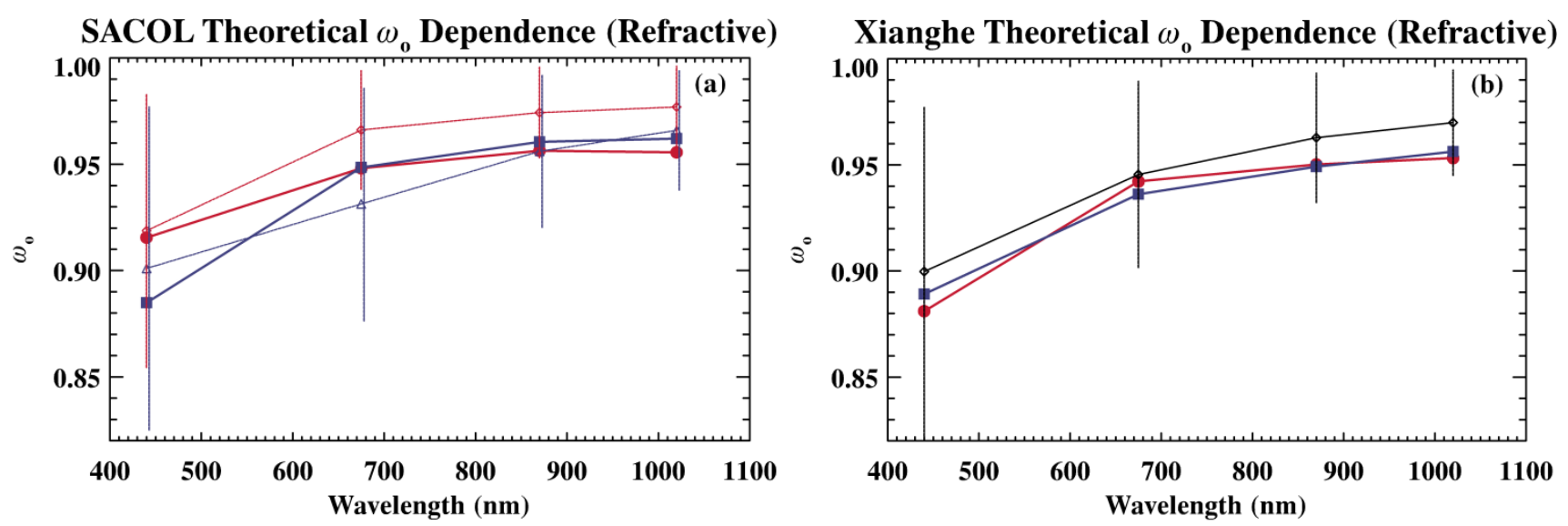

Taihu Theoretical $\omega_{0}$ Dependence (Refractive)

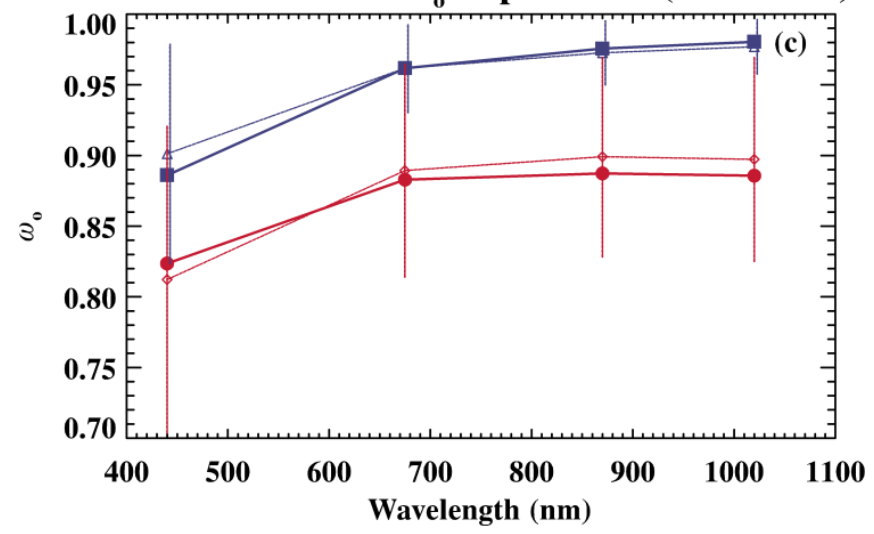

At the SACOL site, the model calculated $\omega_{o}(\lambda)$ agrees well with observation in the visible but overestimates in the longer wavelengths for the winter case (red) (Figure 6(a)). The spring case has slightly better agreement in the longer wavelengths $(675$ and $870 \mathrm{~nm})$ but poor agreement otherwise. A possible explanation is due to the fact that two different real indices of refraction $\left(m_{r}\right.$ of 1.46 and 1.57 for winter and spring, respectively) are used which decreases the sensitivity of the modeled results because the optical properties of aerosol mixtures are poorly taken into account using these criteria. The Xianghe site has nearly the same indices of refraction for both the winter and spring cases with only one theoretical calculation (Figure 6(b)) where the model calculation and observation agree to within one standard deviation suggesting more sensitivity of a variable effective radius. This is likely due the aerosols having similar optical properties during both dust events (i.e., similar source regions and carbonaceous influences). 
Table 2. Summary of the theoretical model parameters used in this study.

\begin{tabular}{|c|c|c|c|c|}
\hline & Aspect Ratio & $m_{r}$ & $m_{i}$ & $r_{e f f}(\mu \mathrm{m})$ \\
\hline \multirow{4}{*}{$\begin{array}{l}\text { SACOL (Winter Case) } \\
\text { Fixed refractive index }\end{array}$} & \multirow{4}{*}{$1.5: 1.8$} & 1.50 & 0.005 & 0.7 \\
\hline & & 1.50 & 0.005 & 0.8 \\
\hline & & 1.50 & 0.005 & 0.9 \\
\hline & & 1.50 & 0.005 & 1.0 \\
\hline \multirow{4}{*}{$\begin{array}{l}\text { SACOL (Spring Case) } \\
\text { Fixed refractive index }\end{array}$} & \multirow{4}{*}{$1.5: 1.8$} & 1.60 & 0.005 & 0.7 \\
\hline & & 1.60 & 0.005 & 0.8 \\
\hline & & 1.60 & 0.005 & 0.9 \\
\hline & & 1.60 & 0.005 & 1.0 \\
\hline \multirow{9}{*}{$\begin{array}{l}\text { SACOL (Winter Case) } \\
\text { Fixed effective radius }\end{array}$} & \multirow{9}{*}{$1.5: 1.8$} & 1.40 & 0.001 & 0.8 \\
\hline & & 1.40 & 0.005 & 0.8 \\
\hline & & 1.40 & 0.010 & 0.8 \\
\hline & & 1.50 & 0.001 & 0.8 \\
\hline & & 1.50 & 0.005 & 0.8 \\
\hline & & 1.50 & 0.010 & 0.8 \\
\hline & & 1.60 & 0.001 & 0.8 \\
\hline & & 1.60 & 0.005 & 0.8 \\
\hline & & 1.60 & 0.010 & 0.8 \\
\hline \multirow{9}{*}{$\begin{array}{l}\text { SACOL (Spring Case) } \\
\text { Fixed effective radius }\end{array}$} & \multirow{9}{*}{$1.5: 1.8$} & 1.40 & 0.001 & 1.0 \\
\hline & & 1.40 & 0.005 & 1.0 \\
\hline & & 1.40 & 0.010 & 1.0 \\
\hline & & 1.50 & 0.001 & 1.0 \\
\hline & & 1.50 & 0.005 & 1.0 \\
\hline & & 1.50 & 0.010 & 1.0 \\
\hline & & 1.60 & 0.001 & 1.0 \\
\hline & & 1.60 & 0.005 & 1.0 \\
\hline & & 1.60 & 0.010 & 1.0 \\
\hline \multirow{4}{*}{$\begin{array}{l}\text { Xianghe (Both Cases) } \\
\text { Fixed refractive index }\end{array}$} & \multirow{4}{*}{$1.8: 2.1$} & 1.60 & 0.005 & 1.0 \\
\hline & & 1.60 & 0.005 & 1.1 \\
\hline & & 1.60 & 0.005 & 1.2 \\
\hline & & 1.60 & 0.005 & 1.3 \\
\hline \multirow{3}{*}{$\begin{array}{l}\text { Xianghe (Both Cases) } \\
\text { Fixed effective radius }\end{array}$} & \multirow{3}{*}{$1.8: 2.1$} & 1.60 & 0.001 & 1.0 \\
\hline & & 1.60 & 0.005 & 1.0 \\
\hline & & 1.60 & 0.010 & 1.0 \\
\hline \multirow{5}{*}{$\begin{array}{l}\text { Taihu (Winter Case) } \\
\text { Fixed refractive index }\end{array}$} & \multirow{5}{*}{$1.5: 1.8$} & 1.50 & 0.020 & 0.5 \\
\hline & & 1.50 & 0.020 & 0.6 \\
\hline & & 1.50 & 0.020 & 0.7 \\
\hline & & 1.50 & 0.020 & 0.8 \\
\hline & & 1.50 & 0.020 & 0.9 \\
\hline \multirow{5}{*}{$\begin{array}{l}\text { Taihu (Spring Case) } \\
\text { Fixed effective radius }\end{array}$} & \multirow{5}{*}{$1.2: 1.5$} & 1.50 & 0.005 & 0.5 \\
\hline & & 1.50 & 0.005 & 0.6 \\
\hline & & 1.50 & 0.005 & 0.7 \\
\hline & & 1.50 & 0.005 & 0.8 \\
\hline & & 1.50 & 0.005 & 0.9 \\
\hline \multirow{3}{*}{ Taihu (Winter Case) } & \multirow{3}{*}{$1.5: 1.8$} & 1.50 & 0.010 & 0.6 \\
\hline & & 1.50 & 0.020 & 0.6 \\
\hline & & 1.50 & 0.050 & 0.6 \\
\hline \multirow{3}{*}{ Taihu (Spring Case) } & \multirow{3}{*}{$1.2: 1.5$} & 1.50 & 0.001 & 0.8 \\
\hline & & 1.50 & 0.005 & 0.8 \\
\hline & & 1.50 & 0.010 & 0.8 \\
\hline
\end{tabular}


At Taihu, there is scarcely any agreement between theory and observation for the winter case suggesting that using a fixed $m_{i}$ cannot account for the enhanced absorption from the large amount of carbonaceous aerosols present in this region (Figure 6(c)). In contrast, the spring case shows good agreement especially in the near IR due to the strong mineral dust influence that dominates the aerosol absorptive properties during this episode. It is interesting to note that the stronger absorption in the winter case has $m_{i}$ of nearly five times higher than the spring case (more absorbing pollution aerosols during winter season). In addition to varying the effective radius and holding the index of refraction constant, we now vary the index of refraction and hold the effective radius constant.

When we vary the index of refraction in the model calculations, it is obvious that there is better agreement between the calculations and observations with more variability. This is especially evident at the SACOL and Taihu sites which exhibited different indices of refraction for the winter and spring cases (Figure 7). The calculated $\omega_{0}(\lambda)$ values at SACOL are still higher than the observed ones for the winter case, however, they are within one standard deviation (Figure 7(a)). There is also better agreement in the spring case as well. The Xianghe winter and spring cases do not drastically change because there are no big differences in particle size and index of refraction between the two cases (Figure 7(b)). At the Taihu site, it is evident that varying the index of refraction better accounts for the wide variety of absorbing aerosols in a mineral dust/carbonaceous mixture in both the winter and spring cases (Figure 7(c)).

\subsection{Aerosol Radiative Effect}

To quantitatively estimate the impact of the dust events on the surface and Top-of-Atmosphere (TOA) radiation budgets, we use the AERONET calculated shortwave (SW) aerosol radiative effects (ARE). It is defined as the difference between the net bottom and top of the atmosphere (BOA and TOA) fluxes when dust aerosols are present, as well as the nearby clear-sky days ( $\mathrm{F}^{\downarrow}{ }_{\mathrm{BOA}}$ and $\mathrm{F}^{\uparrow}$ TOA $)$ and modeled SW fluxes without aerosol input $\left(\mathrm{F}^{\downarrow 0}{ }_{\mathrm{BOA}}\right.$ and $\mathrm{F}^{\uparrow 0}$ TOA $)$, and is given by

$$
\triangle \mathrm{ARE}_{\mathrm{BOA}}=\mathrm{F}^{\downarrow}{ }_{\mathrm{BOA}}-\mathrm{F}^{\downarrow 0}{ }_{\mathrm{BOA}}
$$

and

$$
\Delta \mathrm{ARE}_{\mathrm{TOA}}=\mathrm{F}_{\mathrm{TOA}}^{\uparrow}-\mathrm{F}^{\uparrow 0} \mathrm{TOA}
$$

respectively $[24,25]$. This is a simulated product that uses a combination of sky radiance measurements and radiative transfer theory [24,25]. The criteria for selecting the clear days are: (1) $\tau_{440} \leq 0.3$ and (2) clear sky occurrence before and after the dust events.

We note that there is a sharp increase in $\mathrm{ARE}$ during the dust events with $\mathrm{ARE}_{\mathrm{BOA}}>\mathrm{ARE}_{\mathrm{TOA}}$ which suggests a stronger aerosol cooling effect at the surface than at the TOA (Table 3). The strongest ARE is observed at the Taihu site where the ARE values exceed $-155 \mathrm{~W} \cdot \mathrm{m}^{-2}$ near the surface and $-60 \mathrm{~W} \cdot \mathrm{m}^{-2}$ for the TOA spring case. This is due to dust mixing with carbonaceous aerosols (local pollution) leading to an overall enhanced absorption [14]. This is consistent with the [13], [14], and [15] studies that used Shouxian ARM Mobile Facility (AMF), Zhangye AMF, and AERONET data, respectively. 
Table 3. Summary of the AERONET calculated BOA $(2 \mathrm{~km})$ and TOA $(120 \mathrm{~km})$ aerosol radiative effect (ARE) values.

\begin{tabular}{|c|c|c|c|}
\hline \multirow{2}{*}{ AERONET Site } & \multicolumn{3}{|c|}{ BOA ARE Values $\left(\mathrm{W} \cdot \mathrm{m}^{-2}\right)$} \\
\hline & Clear Sky (before) & Dust Event & Clear Sky (after) \\
\hline SACOL (winter) & -52.9 & -101.1 & -60.6 \\
\hline SACOL (spring) & -48.5 & -136.7 & -52.5 \\
\hline Xianghe (winter) & -64.2 & -106.4 & -39.8 \\
\hline Xianghe (spring) & -40.7 & -83.0 & -42.1 \\
\hline Taihu (winter) & -45.5 & -177.3 & -60.0 \\
\hline Taihu (spring) & -66.9 & -155.3 & -40.8 \\
\hline \multirow{2}{*}{ AERONET Site } & \multicolumn{3}{|c|}{ TOA ARE Values $\left(\mathbf{W} \cdot \mathrm{m}^{-2}\right)$} \\
\hline & Clear Sky (before) & Dust Event & Clear Sky (after) \\
\hline SACOL (winter) & -17.0 & -40.9 & -13.1 \\
\hline SACOL (spring) & -4.5 & -40.9 & -8.5 \\
\hline Xianghe (winter) & -15.3 & -46.0 & -8.6 \\
\hline Xianghe (spring) & -17.1 & -29.7 & -9.1 \\
\hline Taihu (winter) & -19.0 & -21.0 & -17.2 \\
\hline Taihu (spring) & -27.3 & -60.4 & -26.5 \\
\hline
\end{tabular}

The clear-sky values were taken just before and after the dust event where $\tau_{440}<0.3$ and the ARE values for both clear-sky and dust events are calculated against the modeled fluxes without aerosol using Equation (2). Note that the Taihu site has the highest mean clear-sky ARE due to persistent haze from numerous nearby urban and industrial influences (i.e., very few "clear day" instances).

\section{Conclusions}

The optical properties of mineral dust from two dust events are analyzed and compared to theoretical calculations in this study. For the winter case, the aerosol properties at SACOL, Xianghe and Taihu are shown to be a mixture of carbonaceous particles (from local sources) and mineral dust as demonstrated by their $\alpha_{440-870}$ values of $0.29,0.48$, and 0.62 , respectively. In contrast, for the spring case their aerosol properties are primarily mineral dust dominant with $\alpha_{440-870}$ of $0.11,0.42$, and 0.15 , respectively. Carbonaceous particles are shown to influence the absorptive properties of the mineral dust in the winter case especially at SACOL and Taihu but less at Xianghe where the $\alpha_{a b s 440-870}$ values are $1.3,1.3$, and 1.8 , respectively. During the spring, higher $\alpha_{a b s 440-870}$ values of 1.7 (SACOL) and 2.5 (Taihu) suggest that mineral dust dominates the absorptive properties of the aerosols. The lower $\alpha_{a b s 440-870}$ value of 1.6 at Xianghe indicates dust with some carbonaceous influences similar to SACOL and Taihu in the winter case.

A theoretical model based on geometric and mathematical calculations is used to compare with the AERONET retrieved aerosol parameters. The AERONET inversion algorithms employ a spheroidal particle shape assumption while the model assumes a tri-axial ellipsoidal shape. We conclude that although shape as well as size is important, the particle absorptive behavior should also be taken into account especially when mixtures of particle types are present. The winter cases at SACOL and Taihu show poor agreement between theory and observation when the effective radius is varied while holding the index of refraction constant. This is due to the wide variety of mineral dust and 
carbonaceous aerosols particles in the mixture that likely have different indices of refraction. Xianghe has similar indices of refraction for both winter and spring cases leading to good agreement between model and observation results. The spring cases exhibited better agreement than the winter cases because mineral dust was more dominant during the spring season at all three sites. Better agreement between theory and observation at all three sites is observed when the index of refraction is varied while holding the effective radius constant. This suggests the model is more sensitive to the particle absorptive properties rather than the size, especially when dealing with retrieving aerosol properties of mineral dust and carbonaceous particle mixtures. In light of these results it should be mentioned that when the index of refraction is held constant while the effective radius varies, there is less variability in the model than when the opposite is done. When aerosols have both similar size and composition (e.g., the Xianghe site), the model and observation results have sufficient agreement such that both scenarios can be used.

\section{Acknowledgements}

The authors are grateful for the SACOL AERONET data provided by Jianping Huang and Wu Zhang, Xianghe AERONET data provided by Pucai Wang and Xiangao Xia, and Taihu AERONET data provided by Ma Ronghua. The theoretical database is provided upon request of the [22]. Figure 1 is provided by [35]. Additional thanks goes to Aaron Kennedy and fellow graduate students for their insightful and helpful comments for this manuscript. This research was supported by the Ministry of Science and Technology of China with award number 2013CB955804 at Beijing Normal University. Researchers at University of North Dakota were supported by NASA EPSCoR CAN under grant NNX11AM15A at University of North Dakota.

\section{References}

1. Li, Z.; Chen, H.; Cribb, M.; Dickerson, R.; Holben, B.; Li, C.; Lu, D.; Luo, Y.; Maring, H.; Shi, G.; Tsay, S.-C.; Wang, P.; Wang, Y.; Xia, X.; Zheng, Y.; Yuan, T.; Zhao, F. Aerosol optical properties and its radiative effects in northern China. J. Geophys. Res. 2007, 112, doi: 10.1029/2006JD007382.

2. Li, Z.; Chen, H.; Cribb, M.; Dickerson, R.; Holben, B.; Li, C.; Lu, D.; Luo, Y.; Maring, H.; Shi, G. Preface to special section on East Asian studies of tropospheric aerosols: An international regional experiment (EAST-AIRE). J. Geophys. Res. 2007, 112, doi: 10.1029/2007JD008853.

3. Tsunematsu, N.; Kai, K.; Matsumoto, T. The influence of synoptic-scale air flow and local circulation on the dust layer height in the north of the Taklimakan Desert. Water Air Soil Pollut. Focus 2005, 5, 175-193.

4. Logan, T.; Xi, B.; Dong, X.; Obrecht, R.; Li, Z.; Cribb, M. A study of Asian dust plumes using satellite, surface, and aircraft measurements during the INTEX-B field experiment. J. Geophys. Res. 2010, 115, doi: 10.1029/2010JD014134.

5. Uematsu, M.; Duce, R.A.; Prospero, J.M.; Chen, L.; Merrill, J.T.; McDonald, R.L. Transport of mineral aerosol from Asia over the North Pacific Ocean. J. Geophys. Res. 1983, 88, 5343-5352.

6. Jordan, C.E.; Dibb, J.E.; Anderson, B.E.; Fuelberg, H.E. Uptake of nitrate and sulfate on dust aerosols during TRACE-P. J. Geophys. Res. 2003, 108, doi: 10.1029/2002JD003101. 
7. Ling, X.-L.; Guo, W.-D.; Zhao, Q.-F.; Zhang, B.D. A case study of a typical dust storm event over the Loess Plateau of Northwest China. Atmos. Oceanic Sci. Lett. 2011, 4, 344-348.

8. Sun, Y.; Zhuang, G.; Wang, Y.; Zhao, X.; Li, J.; Wang, Z.; An, Z. Chemical composition of dust storms in Beijing and implications for the mixing of mineral aerosol with pollution aerosol on the pathway. J. Geophys. Res. 2005, 110, doi: 10.1029/2005JD006054.

9. Yao, X.; Chan, C.K.; Fang, M.; Cadle, S.; Chan, T.; Mulawa, P.; He, K.; Boming, Y. The water-soluble ionic composition of PM2.5 in Shanghai and Beijing, China. Atmos. Environ. 2002, 36, 4223-4234.

10. Logan, T.; Xi, B.; Dong, X.; Li, Z.; Cribb, M. Classification and investigation of Asian aerosol properties. Atmos. Chem. Phys. Discuss. 2012, 12, 18,927-18,958.

11. Rosenfeld, D.; Lohmann, U.; Raga, G.B.; O’Dowd, C.D.; Kulmala, M.; Fuzzi, S.; Reissell, A.; Andreae, M.O. Flood or drought: How do aerosols affect precipitation? Science 2008, 321, doi: $10.1126 /$ science.1160606.

12. Li, Z.; Niu, F.; Fan, J.; Liu, Y.; Rosenfeld, D.; Ding, Y. Long-term impacts of aerosols on the vertical development of clouds and precipitation. Nat. Geosci. 2011, 4, 888-894.

13. Qiu, Y.; Dong, X.; Xi, B.; Wang, Z. Effects of clouds and aerosols on surface radiation budget inferred from DOE AMF at Shouxian, China. Atmos. Ocean. Sci. Lett. 2013, 6, 1-5.

14. Ge, J.M.; Su, J.; Ackerman, T.P.; Fu, Q.; Huang, J.P.; Shi, J.S. Dust aerosol optical properties retrieval and radiative forcing over northwestern China during the China-U.S. joint field experiment. J. Geophys. Res. 2010, 115, doi: 10.1029/2009JD013263.

15. García, O.E.; Díaz, J.P.; Expósito, F.J.; Díaz, A.M.; Dubovik, O.; Derimian, Y.; Dubuisson, P.; Roger, J.-C. Shortwave radiative forcing and efficiency of key aerosol types using AERONET data. Atmos. Chem. Phys. 2012, 12, 5129-5145.

16. Pope, C.A. Air pollution and health—Good news and bad. N. Engl. J. Med. 2004, 351, 1132-1134.

17. Wang, X.; Huang, J.; Zhang, R.; Chen, B.; Bi, J. Surface measurements of aerosol properties over northwest China during ARM China 2008 deployment. J. Geophys. Res. 2010, 115, doi: 10.1029/ 2009JD013467.

18. Xin, J.; Wang, Y.; Li, Z.; Wang, P.; Hao, W.M.; Nordgren, B.L.; Wang, S.; Liu, G.; Wang, L.; Wen, T.; Sun, Y.; Hu, B. Aerosol optical depth (AOD) and Angstrom exponent of aerosols observed by the Chinese Sun Hazemeter Network from August 2004 to September 2005. J. Geophys. Res. 2007, 112, doi: 10.1029/2006JD007075.

19. Eck, T.F.; Holben, B.N.; Dubovik, O.; Smirnov, A.; Goloub, P.; Chen, H.B.; Chatenet, B.; Gomes, L.; Zhang, X.-Y.; Tsay, S.-C.; Ji, Q.; Giles, D.; Slutsker, I. Columnar aerosol optical properties at AERONET sites in central eastern Asia and aerosol transport to the tropical mid-Pacific. J. Geophys. Res. 2005, 110, doi: 10.1029/2004JD005274.

20. Yi, B.; Hsu, C.N.; Yang, P.; Tsay, S.-C. Radiative transfer simulation of dust-like aerosols: Uncertainties from particle shape and refractive index. J. Aer. Sci. 2011, 42, 631-644.

21. Wang, Y.; Xin, J.; Li, Z.; Wang, S.; Wang, P.; Hao, W.M.; Nordgren, B.L.; Chen, H.; Wang, L.; Sun, Y. Seasonal variations in aerosol optical properties over China. J. Geophys. Res. 2011, 116, doi: 10.1029/2010JD015376.

22. Meng, Z.; Yang, P.; Kattawar, G.W.; Bi, L.; Liou, K.N.; Laszlo, I. Single-scattering properties of tri-axial ellipsoidal mineral dust aerosols: A database for application to radiative transfer calculations. J. Aer. Sci. 2010, 41, 501-512. 
23. Holben, B.N.; Eck, T.F.; Slutsker, I.; Tanré, D.; Buis, J.P.; Setzer, A.; Vermote, E.; Reagan, J.A.; Kaufman, Y.J.; Nakajima, T.; Lavenu, F.; Jankowiak, I.; Smirnov, A. AERONET-A federated instrument network and data archive for aerosol characterization. Rem. Sens. Environ. 1998, 66, $1-16$.

24. Holben, B.N.; Eck, T.F.; Slutsker, I.; Smirnov, A.; Sinyuk, A.; Schafer, A.J.; Giles, D.; Dubovik, O. AERONET's version 2.0 quality assurance criteria, remote sensing of atmosphere and clouds. Proc. SPIE. 2006, 6408, doi: 10.1117/12.706524.

25. Dubovik, O.; King, M. A flexible inversion algorithm for retrieval of aerosol optical properties from Sun and sky radiance measurements. J. Geophys. Res. 2000, 105, 20673-20696.

26. Dubovik, O.; Smirnov, A.; Holben, B.N.; Eck, T.F.; King, M.D.; Kaufman, Y.J.; Slutsker, I. Accuracy assessments of aerosol optical properties retrieved from Aerosol Robotic Network (AERONET) Sun and sky radiance measurements. J. Geophys. Res. 2000, 105, 9791-9806.

27. Ackerman, P.; Toon, O.B. Absorption of visible radiation in atmosphere containing mixtures of absorbing and nonabsorbing particles. Appl. Opt. 1981, 20, 3661-3668.

28. Dubovik, O.; Sinyuk, A.; Lapyonok, T.; Holben, B.N.; Mishchenko, M.; Yang, P.; Eck, T.F.; Volten, H.; Munoz, O.; Veihelmann, B.; et al. Application of spheroid models to account for aerosol particle nonsphericity in remote sensing of desert dust. J. Geophys. Res. 2006, 111, doi: 10.1029/2005JD006619.

29. Sun, J.; Zhang, M.; Liu, T. Spatial and temporal characteristics of dust storms in China and its surrounding regions, 1960-1999: Relations to source area and climate. J. Geophys. Res. 2001, 106, 10325-10333.

30. NOAA/ESRL Physical Sciences Division, Boulder Colorado. 2012. Available online: www.esrl.noaa.gov/psd/ (accessed on 8 October 2012).

31. Kalnay, E.; Kanamitsu, M.; Kistler, R.; Collins, W.; Deaven, D.; Gandin, L.; Iredell, M.; Saha, S.; White, G.; Woollen, J.; et al. The NCEP/NCAR reanalysis 40-year project. Bull. Amer. Meteor. Soc. 1996, 77, 437-471.

32. Yang, M.; Howell, S.G.; Zhuang, J.; Huebert, B.J. Attribution of aerosol light absorption to black carbon, brown carbon, and dust in China-Interpretations of atmospheric measurements during EAST-AIRE. Atmos. Chem. Phys. 2009, 9, 2035-2050.

33. Bergstrom, R.W.; Pilewskie, P.; Russell, P.B.; Redemann, J.; Bond, T.C.; Quinn, P.K.; Sierau, B. Spectral absorption properties of atmospheric aerosols. Atmos. Chem. Phys. 2007, 7, 5937-5943.

34. Russell, P.B.; Bergstrom, R.W.; Shinozuka, Y.; Clarke, A.D.; DeCarlo, P.F.; Jimenez, J.L.; Livingston, J.M.; Redemann, J.; Dubovik, O.; Strawa, A. Absorption Angström Exponent in AERONET and related data as an indicator of aerosol composition. Atmos. Chem. Phys. 2010, 10, 1155-1169.

35. NASA World Wind. 2012. Available online: http://worldwind.arc.noaa.gov/features.html (accessed on 1 January 2012).

(C) 2013 by the authors; licensee MDPI, Basel, Switzerland. This article is an open access article distributed under the terms and conditions of the Creative Commons Attribution license (http://creativecommons.org/licenses/by/3.0/). 